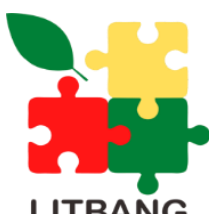

LITBANG

Edusaintech

\section{Jurnal Litbang Edusaintech (JLE)}

http://journal.pwmjateng.com/index.php/jle

\title{
Furzy Geographically Weighted Clustering dengan Gravitational Search Algorithm pada Kasus Penyandang Masalah Kesejahteraan Sosial di Provinsi Jawa Tengah \\ Syayidati Mashfuufab ${ }^{1}$ Indah Manfa'ati Nur ${ }^{1}$ Mob Yamin Darsyah ${ }^{2}$
}

${ }^{1}$ Program Studi Statistika, FMIPA Universitas Muhammadiyah Semarang

${ }^{2}$ Program Studi Ilmu Politik, FISIP UIN Walisongo Semarang

* Correspondence: masfufah@gmail.com

\section{A B S T R A C T S}

One of some indicators of the successful of social welfare development in Central Java was decreasing the population of people with social welfare problems (PMKS). One exertion that can be done was grouping or clustering the areas in Central Java based on 26 indicators of PMKS. Fuzzy Geographcally Weighted Clustering (FGWC) algorithm is a clustering analysis that observing the effect of area. However, FGWC has limitation in initialization centroid phase that makes it trapped to local optimal. The limitation can be addressed with the Gravitational Search Algorithm (GSA) approach. The purpose of GSA was to optimize the value objective function. This research applied FGWC-GSA on PMKS in Central Java Province contained 26 indicators. Some validity indexes were applied to determine the best cluster. This research clustering the areas of Central Java in to two clusters. The first cluster contained 24 districts and cities, and the second cluster contained 11 districts.

\author{
A R T I C L E I N FO \\ Article History: \\ Received 09 Okt 2020 \\ Revised 27 Mei 2021 \\ Accepted 29 Mei 2021 \\ Available online 31 Mei 2021
}

\section{Keyword:}

FGWC,

FGWC-GSA,

PMKS,

Validity Index

\begin{abstract}
A B S T R A K
Salah satu indikator keberhasilan pembangunan kesejahteraan sosial di Jawa Tengah adalah menurunnya jumlah Penyandang Masalah Kesejahteraan Sosial (PMKS). Salah satu upaya yang dapat dilakukan adalah pengelompokan atau pengelompokan wilayah di Jawa Tengah berdasarkan 26 indikator PMKS. Algoritma Fuzzy Geographical Weighted Clustering (FGWC) merupakan analisis clustering yang mengamati efek yang luas. Namun FGWC memiliki keterbatasan dalam inisialisasi fase sentroid yang membuatnya tetap pada optimal lokal. Batasan ini dapat diatasi dengan menggunakan pendekatan Gravitational Search Algorithm (GSA). Tujuan GSA adalah untuk mengoptimalkan fungsi tujuan nilai. Penelitian ini menerapkan FGWC-GSA pada PMKS di Provinsi Jawa Tengah yang terdiri dari 26 indikator. Beberapa indeks validitas diterapkan untuk menentukan cluster terbaik. Studi ini mengelompokkan wilayah Jawa Tengah menjadi dua cluster. Cluster pertama terdiri dari 24 kabupaten dan kota, dan cluster kedua terdiri dari 11 kecamatan.
\end{abstract}

\author{
Keyword: \\ FGWC, \\ FGWC-GSA, \\ PMKS, \\ Indeks Validitas
}




\section{PENDAHULUAN}

Penyandang Masalah Kesejahteraan Sosial (PMKS) adalah perseorangan, keluarga, kelompok, dan atau masyarakat yang mengalami hambatan, kesulitan atau gangguan dan tidak dapat melaksanakan fungsi sosialnya sehingga kebutuhan hidup baik jasmani, rohani maupun sosial tidak dapat terpenuhi dengan baik secara wajar dan memadai (Rachmawati \& Harini, 2016) (Dinsos DIY, 2019). Pada tahun 2017 PMKS di Jawa Tengah turun sekitar 42 ribu sejumlah 4.92 juta sedangkan pada tahun 2016 sejumlah 4.96 juta.

Salah satu indikator keberhasilan pembangunan kesejahteraan sosial di Jawa Tengah adalah semakin berkurangnya populasi Penyandang Masalah Kesejahteraan Sosial (PMKS) (Dinsos Jateng, 2017). Suatu analisis perlu dilakukan untuk mendukung penanganan PMKS dan menciptakan usaha kesejahteraan sosial. Salah satu hal yang dapat dilakukan yaitu pengelompokkan data PMKS sesuai dengan karakteristik masing-masing wilayah (Bappeda, 2013) dengan analisis klaster.

Analisis klaster atau klastering merupakan teknik unsupervised learning (Saha \& Das, 2017). Klastering merupakan suatu proses untuk membagi data menjadi beberapa kelompok sehingga objek dalam satu kelompok memiliki tingkat kemiripan yang besar dan sangat berbeda dengan objek pada kelompok lain (Han, Kamber, \& Pei, 2012). Salah satu algoritma klatering yang telah sering digunakan dalam penelitian adalah algoritma Fuz:y C-Means.

Fuzyy C-Means (FCM) pertama kali diperkenalkan oleh Dunn (1973) kemudian dikembangkan oleh Bezdek (1981). FCM menghubungkan derajat keanggotaan dan jarak suatu objek pada pusat kelompoknya. Suatu objek akan cenderung menjadi anggota suatu kelompok jika objek tersebut memiliki nilai derajat keanggotaan tertinggi (Hadi, 2017).

Furay Geographically Weighted Clustering (FGWC) adalah algoritma klastering yang merupakan perbaikan dari algoritma Fuz:y CMeans (FCM). Pada algoritma FGWC efek kewilayahan telah diperhitungkan pada penghitungan nilai keanggotaannya (Mason \& Jacobson, 2007). Penelitian (Son, Cuong, Lanzi, \& Thong, 2012) (Son, Lanzi, Cuong, \& Hung, 2013) telah menyatakan bahwa FGWC merupakan algoritma yang sesuai digunakan untuk efek kewilayahan. Namun FGWC mudah terjebak ke dalam lokal optima. Hal tersebut disebabkan inisialisasi pusat awal klaster dilakukan secara acak
(Nurmala \& Purwarianti, 2017). Untuk menangani keterbatasan tersebut digunakan Gravitational Search Algorithm (GSA). GSA merupakan salah satu metode optimasi heuristic (Mulyanto \& Wahono, 2015) yang berfokus mendapatkan solusi global dengan mengoptimalkan nilai fungsi objektif agar tidak terjebak pada lokal optima sehingga menghasilkan kualitas klaster yang baik. Penelitian dengan menggunakan algoritma FGWC-GSA pernah dilakukan oleh (Pamungkas \& Pramana, 2018).

Pada penelitian ini pengelompokkan wilayah kabupaten / kota di Jawa Tengah dilakukan dengan algoritma FGWC yang diintegrasikan dengan GSA. Untuk memilih kelompok terbaik, digunakan indeks validitas Partition Coefficient Index, Classification Entropy Index, Separation Index, Xie Beni Index dan IFV Index.

\section{METODE PENELITIAN}

\subsection{Teknik Pengumpulan Data}

Furzy Geographically Weighted Clustering (FGWC) pertama kali diperkenalkan oleh G.A Mason dan Jacobson Tahun 2007 (Mason \& Jacobson, 2007). FGWC merupakan perbaikan dari algoritma FCM yang lebih peka terhadap geografis karena melibatkan efek populasi dan jarak dalam perhitungan derajat keanggotaan pada tiap observasinya (Hadi, 2017). Penghitungan nilai membership pada FGWC ditunjukkan oleh rumus berikut ini (Mason \& Jacobson, 2007).

$$
\mu_{i}^{\prime}=\alpha \mu_{i}+\beta \frac{1}{A} \sum_{j}^{n} w_{i j} \mu_{j}
$$

$\mu_{i}^{\prime}$ merupakan nilai membership baru dari objek i, $\mu_{i}$ merupakan nilai membership lama pada objek i, $w_{i j}$ adalah ukuran penimbang. Nilai $\alpha$ dan $\beta$ didefiniskan sebagai berikut.

$$
\alpha+\beta=1
$$

Penimbang keanggotaan didefiniskan sebagai berikut:

$$
w_{i j}=\frac{\left(m_{i} m_{j}\right)^{b}}{d_{i j}^{a}}
$$

$m_{i}$ adalah jumlah populasi wilayah $i, m_{j}$ adalah jumlah populasi dari wilayah $\mathrm{j}, d_{i j}$ merupakan jawak antar wilayah i dan wilayah j. a dan b bernilai 1.

Ketebatasan FGWC yang mudah terjebak ke dalam local optima dapat ditangani dengan Gravitational Search Algorithm (GSA) yang diusulkan oleh Rashedi pada Tahun 2009 (Rashedi, Nezamabadi-pour, \& Saryazdi, 2009) dengan meminimumkan nilai fungsi objektif FGWC. 
Fungsi objektif FGWC didefinisikan sebagai berikut.

$J_{F G W C}(U, V ; X)=\sum_{i=1}^{C} \sum_{k=1}^{n} u_{i k}^{m}\left|v_{i}-x_{k}\right|^{2} \rightarrow \min$ (4)

$U$ adalah matriks keanggotaan, $V$ adalah matriks untuk pusat klaster, $X$ adalah matriks untuk data, $v_{i}$ adalah pusat klaster untuk objek $-i$, dan $u_{i}$ adalah elemen dari matriks keanggotaan, serta $x_{k}$ merupakan itik data.

Pusat klaster didefinisikan sebagai berikut:

$$
v_{i}=\frac{\sum_{k=1}^{n} u_{i k}^{m} x_{k}}{\sum_{k=1}^{n} u_{i k}^{m}}
$$

Serta matriks keanggotaan dapat dihitung dengan rumus berikut

$$
u_{i k}=\frac{1}{\sum_{j=1}^{c}\left(\frac{\left\|v_{i}-x_{k}\right\|}{\left\|v_{j}-x_{k}\right\|}\right)^{\frac{2}{m-1}}}
$$

\section{Gravitational Search Algorithm (GSA)}

GSA memiliki tujuan untuk memperbaiki ekplorasi dan eksploitasi populasi berbasis algoritma untuk mencapai solusi optimal. GSA terinspirasi dari hukum gerakan dan gravitasi Newton.

Langkah pertama dalam GSA adalah inisialisasi secara acak nilai agen. Kemudian menghitung gaya total pada masing-masing agen dengan rumus berikut.

$$
F_{i j}^{d}(t)=G(t) \frac{M_{i}(t) M_{j}(t)}{R_{i j}(t)}\left(x_{i}^{d}(t)-x_{i}^{d}(t)\right)(7)
$$

Dimana $x_{i}^{d}$ menunjukkan posisi agen, $(t)$ adalah konstan gravitasi pada $t, M_{i}$ adalah massa dari agen $i$ dan $R_{i j}(t)$ adalah jarak Euclidean di antara agen.

$$
R_{i j}(t)=\left\|X_{i}(t), X_{j}(t)\right\|_{2}
$$

berikut:

Massa agen $M_{i}(t)$ didefinisikan sebagai

$$
\begin{aligned}
& m_{i}(t)=\frac{\operatorname{fit}_{i}(t)-\operatorname{worst}(t)}{\operatorname{best}(t)-\operatorname{worst}(t)} \\
& M_{i}(t)=\frac{m_{i}(t)}{\sum_{j=1}^{N} m_{j}(t)}
\end{aligned}
$$

fit $_{i}(t)$ merupakan nilai fitness dari solusi. The best dan the worst ditentukan oleh nilai fitness tersebut. Berikut ini ada dua fungsi untuk meminimumkan the best dan the worst.

$$
\operatorname{best}(t)=\min _{j \in\{1 \ldots N\}} f_{i t}(t)
$$

$$
\operatorname{worst}(t)=\max _{j \in\{1 \ldots N\}} f i t_{j}(t)
$$

Percepatan $(a)$ dan kecepatan $(v)$ masingmasing agen didefinisikan sebagai berikut:

$$
\begin{gathered}
a_{i}^{d}(t)=\frac{F_{i}^{d}(t)}{M_{i}(t)} \\
v_{i}^{d}(t+1)=\operatorname{rand}_{i} \times v_{i}^{d}(t) \times a_{i}^{d}
\end{gathered}
$$

Langkah terakhir adalah update posisi masingmasing agen $x$

$$
x_{i}^{d}(t+1)=x_{i}^{d}(t)+v_{i}^{d}(t+1)
$$


Ulangi langkah di atas hingga iterasi maksimum atau hingga kriteria berhenti terpenuhi.

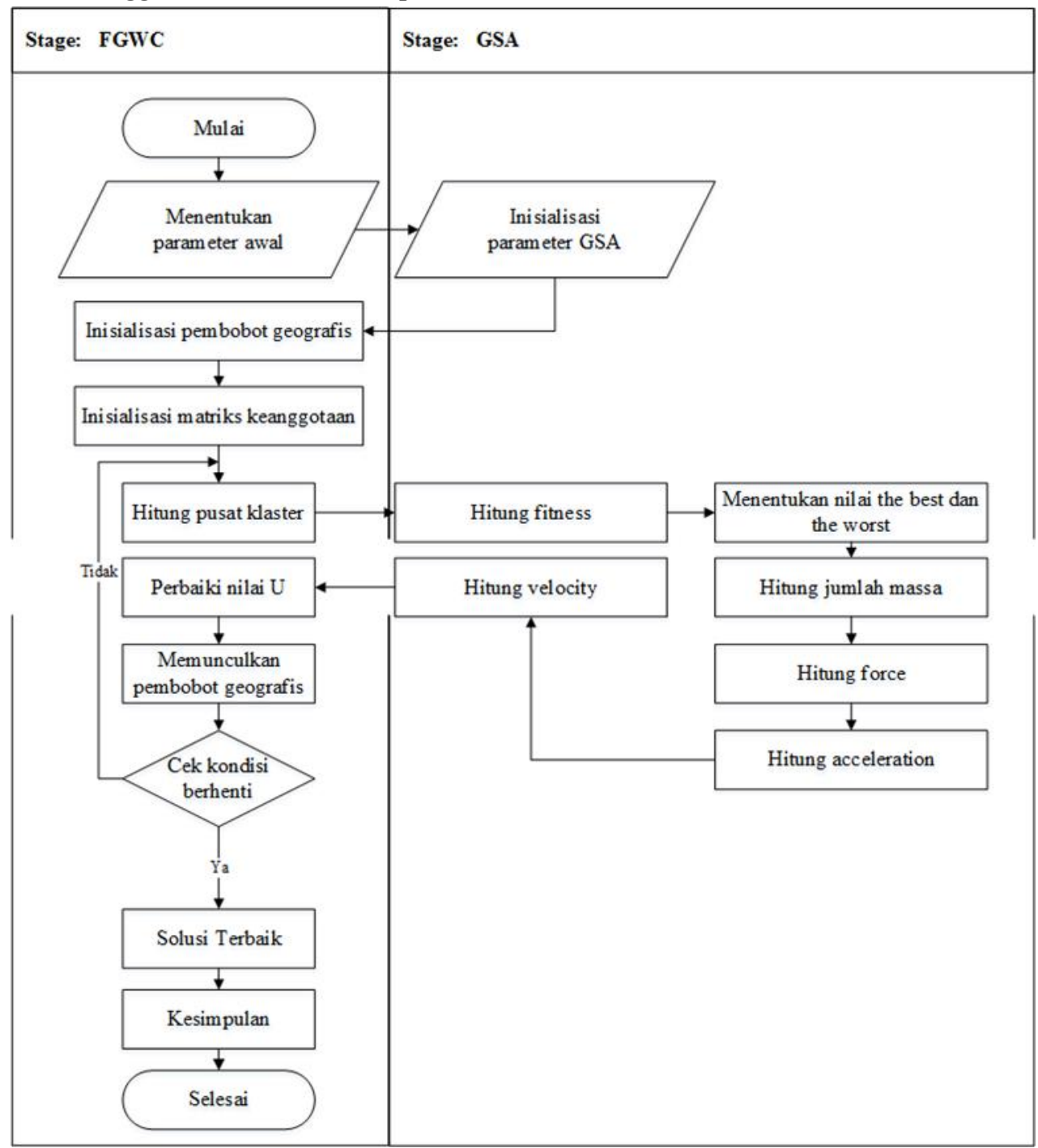

Gambar 1. Diagram Alir Penelitian

Permasalahan utama dalam analisis klastering adalah menentukan jumlah klaster optimal yang akan digunakan untuk pengelompokkan. Untuk itu perlu sebuah indeks validitas klaster yang memiliki tujuan penentuan kriteria objektif untuk menentukan nilai partisi dari algoritma klastering sehingga diperoleh klaster optimal (Mashfuufah \& Istiawan, 2018). Pada penelitian ini, digunakan beberapa indeks validitas yaitu Partition Coefficient Index (PCI), Classification Entropy Index (CEI), Separation Index (SI), Xie Beni Index (XBI) and IFV Index.

\section{Partition Coefficient Index (PCI)}

PCI menghitung nilai rata-rata dari derajat keanggotaan pada masing-masing objek dalam matriks keanggotaan (Bezdek, 1981). Klaster optimal diperoleh ketika nilai PCI maksimum.

$$
P C I=\frac{1}{N}\left(\sum_{i=1}^{c} \sum_{j=1}^{N} \mu_{i j}^{2}\right)
$$

Classification Entropy Index (CEI)

CEI digunakan untuk menentukan kesamaran dari partisi kelompok. Klaster terbaik diperoleh ketika nilai CEI minimum.

$$
C E I=-\frac{1}{N} \sum_{i=1}^{c} \sum_{j=1}^{N} \mu_{i j} \log \mu_{i j}
$$

Separation Index (SI)

SI menghitung kekompakkan dan separasi pada masing-masing klaster. Klaster terbaik diperoleh ketika nilai SI minimum.

$$
S I=\frac{\sum_{i=1}^{c} \sum_{j=1}^{N}\left(\mu_{i j}\right)^{2}\left\|x_{j}-v_{i}\right\|^{2}}{N \min _{i, k}\left\|v_{k}-v_{i}\right\|^{2}}
$$

Xie Beni Index (XBI) 
XBI bertujuan menghitung rasio dari total varians dalam klaster dan pemisahan klaster (Xie \& Beni, 1991). Klaster terbaik diperoleh ketika nilai XBI minimum.

$$
X B I=\frac{\sum_{i=1}^{c} \sum_{j=1}^{N}\left(\mu_{i j}\right)^{m}\left\|x_{j}-v_{i}\right\|^{2}}{N \min _{i, j}\left\|v_{k}-v_{i}\right\|^{2}}
$$

IFV Index

IFV sering digunakan untuk memvalidasi pengelompokkan furzy dengan data spasial, karena sifatnya yang robust dan stabil. Ketika nilai IFV maksimum maka kualitas klaster semakin baik. Ukuran persamaannya diuraikan sebagai berikut (Hu, Meng, \& Shi, 2008).

$$
\begin{aligned}
& I F V=\frac{1}{c} \sum_{j=1}^{c}\left\{\frac { 1 } { N } \sum _ { k = 1 } ^ { N } \mu _ { k j } ^ { 2 } \left[\log _{2} c-\right.\right. \\
& \left.\left.\frac{1}{N} \sum_{k=1}^{N} \log _{2} \mu_{k j}\right]^{2}\right\} \frac{S D \max }{\overline{\sigma_{D}}} \\
& S D_{\max }=\max _{k \neq j}\left\|V_{k}-V_{j}\right\|^{2} \\
& \overline{\sigma_{D}}=\frac{1}{c} \sum_{j=1}^{c}\left(\frac{1}{N} \sum_{k=1}^{N}\left\|X_{k}-V_{j}\right\|^{2}\right)
\end{aligned}
$$

Berikut ini adalah langkah-langkah penelitian yang dilakukan.

1. Memulai dengan mempersiapkan data

2. Parameter awal FGWC yaitu menentukan jumlah klaster (c), nilai fuzziness $(m)$, iterasi maksimum, nilai threshold dan parameter fungsi pembobot

3. Menginisialisasi parameter GSA yaitu nilai agen dan gravitasi konstan

4. Menginisialisasi pembobot geografis dengan rumus (3)

5. Menginisialisasi matriks keanggotaan dengan rumus (2)

6. Menghitung pusat klaster dengan rumus (5)

7. Menentukan nilai fitness dengan rumus (4)

8. Menentukan the best dan the worst

9. Menghitung jumlah massa dengan rumus (10)
10. Menghitung percepatan dengan rumus (11)

11. Menghitung gaya dengan rumus (7)

12. Menghitung kecepatan dengan rumus (12)

13. Memperbaiki nilai matriks keanggotaan dengan rumus (6)

14. Memunculkan matriks keanggoaan dengan pembobot geografis

15. Mengamati kriteria pemberhentian. Hal ini berguna untuk melihat apakah kriteria pemberhentian sudah terpenuhi atau belum. Jika belum terpenuhi, maka mengulangi tahapan mulai dari tahap lima

16. Menentukan solusi terbaik. Solusi terbaik diperoleh dari kriteria hasil indeks validitas.

17. Menarik kesimpulan.

18. Selesai

\section{HASIL DAN PEMBAHASAN}

Data yang digunakan pada penelitian ini adalah data sekunder Penyandang Masalah Kesejahteraan Sosial (PMKS) di Provinsi Jawa Tengah tahun 2017 yang diperoleh dari Dinas Sosial Provinsi Jawa Tengah. Data tersebut terdiri dari 26 variabel indikator PMKS dan sejumlah 35 unit observasi yaitu 29 Kabupaten dan 6 kota di Jawa Tengah.

Tabel 1. di bawah ini merupakan hasil evaluasi indeks validitas pada percobaan klaster dua hingga delapan. Nilai dengan huruf tebal merupakan klaster optimal yang ditentukan oleh masing-masing indeks validitas.

Tabel 1. Nilai Indeks Validitas Masing-masing Klaster

\begin{tabular}{cccccc}
\hline Klaster & PCI & CEI & SI & XBI & IFV Indeks \\
\hline 2 & $\mathbf{0 . 8 0 8 5 7}$ & $\mathbf{0 . 3 1 6 8 4}$ & $\mathbf{0 . 3 3 5 3 1}$ & $\mathbf{0 . 3 3 5 3 1}$ & 98.27078 \\
3 & 0.68225 & 0.56811 & 0.84105 & 0.84105 & 193.68791 \\
4 & 0.55029 & 0.83301 & 4.53380 & 4.53380 & 171.71962 \\
5 & 0.51231 & 0.90877 & $3.09 \mathrm{E}+12$ & $3.09 \mathrm{E}+12$ & 184.2751 \\
\hline
\end{tabular}




\begin{tabular}{cccccc}
\hline Klaster & PCI & CEI & SI & XBI & IFV Indeks \\
\hline 6 & 0.46759 & 1.03720 & $3.90 \mathrm{E}+07$ & $3.90 \mathrm{E}+07$ & 199.1942 \\
7 & 0.44085 & 1.12455 & $2.91 \mathrm{E}+10$ & $2.91 \mathrm{E}+10$ & 309.4207 \\
8 & 0.39416 & 1.28330 & $6.69 \mathrm{E}+12$ & $6.69 \mathrm{E}+12$ & $\mathbf{4 1 4 . 6 8 9 3}$ \\
\hline
\end{tabular}

Dari tabel 1. dapat diketahui bahwa indeks validitas PCI, CEI, SI dan XBI memberikan nilai maksimum pada percobaan klaster ke dua. Sedangkan IFV Indeks memberikan nilai maksimum pada percobaan klaster ke delapan. Dari ke lima indeks validitas yang digunakan sebagai evaluasi klaster optimal, empat diantaranya memberikan klaster optimal yaitu dua klaster. Untuk itu, pengelompokkan Kabupaten /kota di Jawa Tengah berdasarkan 26 indikator PMKS.

Setelah melakukan pengelompokkan menggunakan algoritma FGWC-GSA, dilakukan visualisasi hasil pengelompokkan dalam bentuk peta pada gambar 2. berikut ini

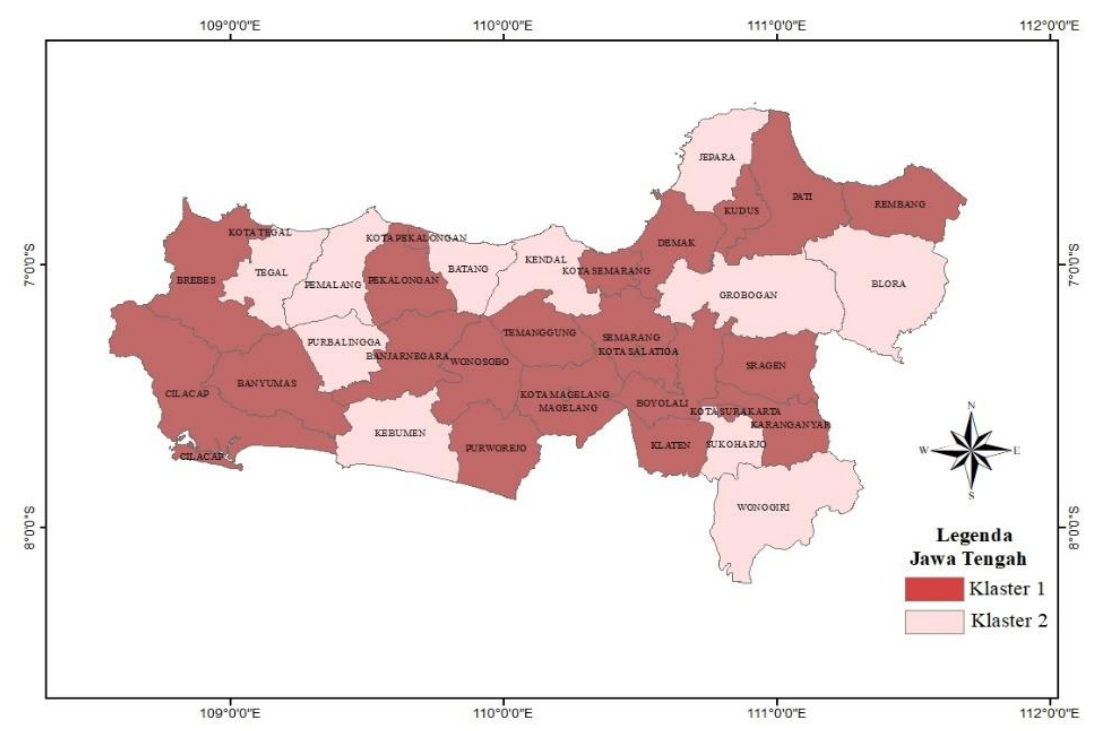

Gambar 2. Peta hasil pengelompokkan

Wilayah yang diberi warna merah gelap merupakan wilayah yang menjadi bagian dari klaster pertama sedangkan wilayah yang diberi warna merah terang merupakan wilayah yang menjadi bagian dari klaster kedua. Berikut ini disajikan tabel keanggotaan pada masingmasing klaster.

Tabel 2. Keanggotaan Masing-masing Klaster

\begin{tabular}{ll|l}
\hline \multicolumn{2}{c|}{ Klaster 1 } & \multicolumn{1}{c}{ Klaster 2 } \\
\hline Kabupaten Cilacap & Kabupaten Kudus & Kabupaten Kendal \\
Kabupaten Banyumas & Kabupaten Demak & Kabupaten Batang \\
Kabupaten Banjarnegara & Kabupaten Semarang & Kabupaten Pemalang \\
Kabupaten Purworejo & Kabupaten Temanggung & Kabupaten Tegal
\end{tabular}




\begin{tabular}{|c|c|c|}
\hline \multicolumn{2}{|c|}{ Klaster 1} & Klaster 2 \\
\hline Kabupaten Wonosobo & Kabupaten Pekalongan & $\begin{array}{l}\text { Kabupaten } \\
\text { Purbalingga }\end{array}$ \\
\hline Kabupaten Magelang & Kabupaten Brebes & Kabupaten Kebumen \\
\hline Kabupaten Boyolali & Kota Magelang & Kabupaten Sukoharjo \\
\hline Kabupaten Klaten & Kota Surakarta & Kabupaten Wonogiri \\
\hline Kabupaten Karanganyar & Kota Salatiga & Kabupaten Grobogan \\
\hline Kabupaten Sragen & Kota Semarang & Kabupaten Blora \\
\hline Kabupaten Rembang & Kota Pekalongan & Kabupaten Jepara \\
\hline Kabupaten Pati & Kota Tegal & \\
\hline
\end{tabular}

Klaster pertama beranggotakan 18 kabupaten dan 6 kota di Jawa Tengah, sedangkan klaster kedua beranggotakan 11 kabupaten di Jawa Tengah. Berdasarkan indicator PMKS, karakteristik dari masingmasing klaster adalah sebagai berikut:

1. Klaster pertama memiliki karakteristik wilayah yang memiliki jumlah anak balita terlantar besar, jumlah anak terlantar besar, jumlah anak jalanan besar, jumlah anak yang memerlukan perlindungan khusus besar, jumlah lanjut usia terlantar besar, jumlah pengemis besar, jumlah pemulung besar, jumlah kelompok minoritas besar, jumlah bekas warga binaan Lembaga pemasyarakatan besar, jumlah korban trafficking besar jumlah korbaan tindak kekerasan besar, jumlah korban bencana alam besar, jumlah perempuan rawan sosial ekonomi besar dan jumlah komunitas adat terpencil besar.

2. Klaster kedua memiliki karakteristik wilayah yang memiliki jumlah anak berhadapan hokum besar, jumlah anak dengan kedisabilitasan besar, jumlah anak yang menjadi tindak kekerasan besar, jumlah penyandang disabilitas besar, jumlah tuna susila besar, jumlah gelandangan besar, jumlah orang dengan HIV/AIDS besar, jumlah korban penyalahgunaan napza besar, jumlah pekerja migran bermasalah sosial besar, jumlah korban bencana sosial besar, jumlah fakir miskin besar dan jumlah keluarga bermasalah sosial psikologis besar.

\section{KESIMPULAN}

Berdasarkan uraian pada hasil dan pembahasan, dapat disimpulkan beberapa hal yaitu:

1. Berdasarkan hasil evaluasi klaster menggunakan indeks validitas PCI, CEI, SI, XBI dan IFV Indeks diperoleh hasil bahwa empat dari lima indeks validitas yang digunakan menunjukkan bahwa klaster optimal untuk pengelompokkan kabupaten / kota di Jawa Tengah berdasarkan 26 indiakator PMKS adalah dua klaster/kelompok.

2. Hasil pengelompokkan kabupaten / kota di Jawa Tengah berdasarkan 26 indikator PMKS dengan menggunakan algoritma FGWC-GSA adalah sebagai berikut.

a. Klaster 1 terdiri dari Kabupaten Cilacap, Kabupaten Banyumas, Kabupaten Purworejo, Kabupaten Wonosobo, Kabupaten Kudus, Kabupaten Demak, Kabupaten Semarang, Kabupaten Temanggung, Kabupaten Pekalongan, Kabupaten Magelang, Kabupaten Boyolali, Kabupaten Klaten, Kabupaten Karanganyar, Kabupaten Sragen, Kabupaten Rembang, Kabupaten Pati, Kabupaten Brebes, Kota Magelang, Kota Surakarta, Kota Salatiga, Kota 
Semarang, Kota Pekalongan dan Kota Tegal.

Karakteristik pada klaster 1 adalah wilayah yang memiliki jumlah anak balita terlantar besar, jumlah anak terlantar besar, jumlah anak jalanan besar, jumlah anak yang memerlukan perlindungan khusus besar, jumlah lanjut usia terlantar besar, jumlah pengemis besar, jumlah pemulung besar, jumlah kelompok minoritas besar, jumlah bekas warga binaan Lembaga pemasyarakatan besar, jumlah korban trafficking besar jumlah korbaan tindak kekerasan besar, jumlah korban bencana alam besar, jumlah perempuan rawan sosial ekonomi besar dan jumlah komunitas adat terpencil besar

b. Klaster 2 terdiri dari Kabupaten Kendal, Kabupaten Batang, Kabupaten Pemalang, Kabupaten Tegal, Kabupaten Purbalingga, Kabupaten Kebumen, Kabupaten Wonogiri, Kabupaten Grobogan, Kabupaten Blora dan Kabupaten Jepara.

Karakteristik pada klaster 2 adalah wilayah yang memiliki jumlah anak berhadapan hokum besar, jumlah anak dengan kedisabilitasan besar, jumlah anak yang menjadi tindak kekerasan besar, jumlah penyandang disabilitas besar, jumlah tuna susila besar, jumlah gelandangan besar, jumlah orang dengan HIV/AIDS besar, jumlah korban penyalahgunaan napza besar, jumlah pekerja migran bermasalah sosial besar, jumlah korban bencana sosial besar, jumlah fakir miskin besar dan jumlah keluarga bermasalah sosial psikologis besar.

\section{ACKNOWLEDGMENT}

Ucapan terimakasih kami ucapkan kepada Pemerintah Provinsi Jawa Tengah dan BPS Provinsi Jawa Tengah atas fasilitas data yang bisa kami akses serta Laboratorium Statistika UNIMUS yang telah memfasilitasi penelitian ini. 


\section{REFERENCES}

Bappeda. (2013). Kajian Penyandang Masalab Kesejabteraan Sosial (PMKS). Kabupaten Temanggung.

Bezdek, J. C. (1981). Pattern Recognition with Furay Objective Function Algorithms. (M. Nadler, Ed.) (1st ed.). New York: Springer. https://doi.org/DOI 10.1007/978-1-4757-0450-1

Dinsos DIY. (2019). Buku Panduan Pemutakhiran Data PMKS dan PSKS TAHUN 2019. Yogyakarta: Dinas Sosial Daerah Istimewa Yogyakarta.

Dinsos Jateng. (2017). Data Penyandang Masalah Kesejahteraan Sosial Tahun 2017. Semarang: Dinas Sosial Provinsi Jawa Tengah.

Hadi, B. S. (2017). Pendekatan Modified Partikel Swarm Optimazion dan Artificial Bee Colony Pada Fugy Geographically. Institut Teknologi Sepuluh Nopember.

Han, J., Kamber, M., \& Pei, J. (2012). Data Mining Concepts and Techniques (Third). Morgan Kaufmann.

Hu, C., Meng, L., \& Shi, W. (2008). Fuzzy Clustering Validity for Spatial Data. Geo-Spatial Information Science, 11(3), 191-196. https://doi.org/10.1007/s11806-008-0094-8

Mashfuufah, S., \& Istiawan, D. (2018). Penerapan Partition Entropy Index, Partition Coefficient Index dan Xie Beni Index untuk Penentuan Jumlah Klaster Optimal pada Algoritma Fuzzy C-Means dalam Pemetaan Tingkat Kesejahteraan Penduduk Jawa Tengah. The 7th University Research Colloqium, 51-60.

Mason, G. a, \& Jacobson, R. D. (2007). Fuzzy Geographically Weighted Clustering. Proceedings of the 9th International Conference on Geocomputation, (1998), 1-7.

Mulyanto, A., \& Wahono, R. S. (2015). Penerapan Gravitational Search Algorithm untuk Optimasi Klasterisasi Fuzzy C-Means. Journal of Intelligent Systems, 1(1), 42-47.

Nurmala, N., \& Purwarianti, A. (2017). Improvement of Fuzzy Geographically Weighted Clustering-Ant Colony Optimization Performance using Context-Based Clustering and CUDA Parallel Programming. Journal of ICT Research and Applications, 11(1), 21-37. https://doi.org/10.5614/itbj.ict.res.appl.2017.11.1.2

Pamungkas, I. H., \& Pramana, S. (2018). Improvement Method Of Fuzzy Geographically Weighted Clustering Using Gravitational Searcch Algorithm. Jurnal Ilmu Komputer Dan Informasi, 1, 10-16. https://doi.org/http://dx.doi.org/10.21609/jiki.v11i1.580

Rachmawati, T. R., \& Harini, D. (2016). Analisis Kinerja Organisasi di Dinas Sosial, Tenaga Kerja, dan Transmigrasi Kabupaten Semarang (Studi Kasus Pada Bidang Sosial Pelayanan Bantuan Dan Jaminan Sosial Terhadap Penyandang Masalah Kesejahteraan Sosial). Journal of Public Policy And Management Review, 5(2).

Rashedi, E., Nezamabadi-pour, H., \& Saryazdi, S. (2009). GSA: A Gravitational Search Algorithm. Information Sciences, 179(13), 2232-2248. https://doi.org/10.1016/j.ins.2009.03.004

Saha, A., \& Das, S. (2017). Axiomatic Generalization of the Membership Degree Weighting Function for Fuzzy C Means Clustering: Theoretical Development and Convergence 
Analysis. Information Sciences. https://doi.org/10.1016/j.ins.2017.03.024

Son, L. H., Cuong, B. C., Lanzi, P. L., \& Thong, N. T. (2012). A Novel Intuitionistic Fuzzy Clustering Method for Geo-Demographic Analysis. Expert Systems with Applications, 39(10), 9848-9859. https://doi.org/10.1016/j.eswa.2012.02.167

Son, L. H., Lanzi, P. L., Cuong, B. C., \& Hung, H. A. (2013). Data Mining in GIS: A Novel Context-Based Fuzzy Geographically Weighted ClusteringAlgorithm. International Journal of Machine Learning and Computing, 2(3), 235-238. https://doi.org/10.7763/ijmlc.2012.v2.121

Xie, X. L., \& Beni, G. (1991). A Validity Measure for Fuzzy Clustering. IEEE Transactions on Pattern Analysis and Machine Intelligence, 13(841-847). 